University of Nebraska - Lincoln

DigitalCommons@University of Nebraska - Lincoln

USDA Forest Service / UNL Faculty Publications U.S. Department of Agriculture: Forest Service -National Agroforestry Center

March 2007

\title{
Developing above-ground woody biomass equations for open- grown, multiple-stemmed tree species: Shelterbelt-grown Russian-olive
}

\author{
Xinhua Zhou \\ University of Nebraska - Lincoln, xzhou2@unl.edu \\ James R. Brandle \\ University of Nebraska - Lincoln, jbrandle1@unl.edu \\ Michele M. Schoeneberger \\ University of Nebraska - Lincoln, mschoeneberger1@unl.edu \\ Tala Awada \\ University of Nebraska - Lincoln, tawada2@unl.edu
}

Follow this and additional works at: https://digitalcommons.unl.edu/usdafsfacpub

Part of the Forest Sciences Commons

Zhou, Xinhua; Brandle, James R.; Schoeneberger, Michele M.; and Awada, Tala , "Developing above-ground woody biomass equations for open-grown, multiple-stemmed tree species: Shelterbelt-grown Russianolive" (2007). USDA Forest Service / UNL Faculty Publications. 26.

https://digitalcommons.unl.edu/usdafsfacpub/26

This Article is brought to you for free and open access by the U.S. Department of Agriculture: Forest Service -National Agroforestry Center at DigitalCommons@University of Nebraska - Lincoln. It has been accepted for inclusion in USDA Forest Service / UNL Faculty Publications by an authorized administrator of DigitalCommons@University of Nebraska - Lincoln. 


\title{
Developing above-ground woody biomass equations for open-grown, multiple-stemmed tree species: Shelterbelt-grown Russian-olive
}

\author{
Xinhua Zhou ${ }^{a, *}$, James R. Brandle ${ }^{a, 1}$, Michele M. Schoeneberger ${ }^{b, 2}$, Tala Awada ${ }^{a, 3}$ \\ a School of Natural Resources, University of Nebraska, Lincoln, NE 68583-0968, USA \\ $\mathrm{b}$ US Forest Service, Southern Research Station, National Agroforestry Center, Lincoln, NE 68583-0822, USA
}

\section{A R T I C L E I N F O}

\section{Article history:}

Received 28 July 2005

Received in revised form

10 October 2006

Accepted 30 October 2006

Published on line 15 December 2006

Keywords:

Agroforestry

Biomass model

Carbon

Elaeagnus angustifolia

Windbreak

Shelterbelt

\begin{abstract}
A B S T R A C T
Multiple-stemmed tree species are often used in agricultural settings, playing a significant role in natural resource conservation and carbon sequestration. Biomass estimation, whether for modeling growth under different climate scenarios, accounting for carbon sequestered, or inclusion in natural resource inventories, requires equations that can accurately describe biomass in these species. Russian-olive (Elaeagnus angustifolia) is a common tree species used in Great Plains shelterbelts and has a growth form typical to open-grown, multiple-stemmed tree species. Using shelterbelt-grown Russian-olive, we present a procedure of choosing predictors, formulating models, and determining equations by optimizing the accuracy in above-ground woody biomass estimates associated with labor costs for opengrown, multiple-stemmed tree species. Trunk (a primary stem) diameter at breast height and/or tree height were satisfactory for trunk biomass prediction but insufficient for determining branch (secondary stems and limbs) biomass, a major component of biomass in these trees. Incorporating the diameters of the three largest stems into the branch biomass equations improved the prediction satisfactorily. Two sets of equations, each of which includes two equations for trunk and branches, respectively, are presented. One set has the cost-saving-preferred (CSP) equations having lower precision but only requiring easily measured DBH variables of trunk and stems. The other set has the precision-preferred (PP) equations that have better precision but at the added cost required for taking an additional measurement of height and the inconvenient measurements of stem diameters at branch bark ridge. Both sets of equations were used to estimate the biomass of the same representative shelterbelts. The results indicated that the PP equations consistently gave better precision for trunk, branches, and whole tree than the CSP equations, but reduced the relative error in whole-tree biomass estimates by only $0.8-1.2 \%$. Ultimately, the decision to use the CSP or the PP equations will depend on the desired precision level and/or available budget. The procedure we have presented, along with the chosen predictors and formulated models, provides a reference for estimating above-ground woody biomass of other open-grown, multiple-stemmed tree species in agricultural settings.
\end{abstract}

(c) 2006 Elsevier B.V. All rights reserved.

\footnotetext{
* Corresponding author. Tel.: +1 402472 9889; fax: +1 4024722946.

E-mail addresses: xzhou2@unl.edu (X.H. Zhou), jbrandle1@unl.edu (J.R. Brandle), mschoeneberger@fs.fed.us (M.M. Schoeneberger), tawada2@unl.edu (T. Awada).

1 Tel.: +1 4024726626 .

2 Tel.: +1 402437 5178x21.

3 Tel.: +1 4024728483 .
}

0304-3800/\$ - see front matter

doi:10.1016/j.ecolmodel.2006.10.024 


\section{Introduction}

Multiple-stemmed tree species are an important component in conservation plantings, such as field windbreaks and living snowfences, and are used throughout the Great Plains (Cunningham, 1988) and other regions (Nicholas, 1988). A good example of these multiple-stemmed tree species is Russian-olive (Elaeagnus angustifolia L., Fig. 1A). It has an irregular globe shape (Fig. 1A) and multiple stems (Fig. 1B). Its stems, branching out of a primary stem (trunk) near, at, and even below the groundline (Fig. 1C), distinguish Russian-olive from most single-stemmed trees. And its obvious trunk and the greater variability in stem diameters distinguish it from shrubs. Planted extensively during the 1930s (Bagley and Sutton, 2002), Russian-olive continues to be an important component of shelterbelts, especially in the drier areas of the Great Plains (Stannard et al., 2002). Biomass estimation of these multiple-stemmed trees, whether for modeling growth under different climate scenarios [e.g., SEEDSCAPE (Guo, 2000; Easterling et al., 2001)], accounting for carbon sequestered (Montagnini and Nair, 2004), or inclusion in natural resource inventories (Chojnacky and Rogers, 1999), requires equations that can accurately describe biomass in these species, as well as measurement protocol that can be easily and economically executed.

The methodologies of developing biomass equations for single-stemmed trees are well documented (Ter-Mikaelian and KorzukhinECOMOD4577BIB271997) and are generally based on trunk diameter and/or height measurements. Due to their branchiness, multiple-stemmed species at a given diameter and/or height have considerable variability in their biomass. Various methods have been used to develop the equations for these species; the most common being the use of allometric relationships between biomass and diameter at different heights. In equations for several species of small multiple-stemmed trees (diameter $<7 \mathrm{~cm}$ ), Telfer (1969) and Brown (1976) used diameter at groundline, Grigal and Ohmann (1977) and Brand and Smith (1985) used diameter at a height of $15 \mathrm{~cm}$, and Roussopoulos and Loomis (1979) used diameter at a height of $1.37 \mathrm{~m}$ (breast height). For small multiple-stemmed trees (trunk diameter $<3.5 \mathrm{~cm}$ ), understory trees, and shrubs, other predictors such as crown diameter (Ohmann et al., 1976); crown percent cover (Ohmann et al., 1981); stem number, crown volume, and shrub height (Peek, 1970) were used in biomass equations.

Unfortunately, none of these equations are suitable for multiple-stemmed trees species, especially those growing under the more open-grown conditions common in agricultural settings, such as shelterbelts, riparian forests, small forest tracts, and sparse woodlands. With the greater light exposure and less competition for water and nutrients in these settings, trees tend to allocate a larger portion of growth into canopy biomass than would generally occur in a forest understory (Wittwer et al., 1999). For Russian-olive occurring in agricultural settings, trunk diameter of up to $33 \mathrm{~cm}$ (our field data) and height of up to $9 \mathrm{~m}$ (Dirr, 1983; Bagley and Sutton, 2002) are well beyond the limits of existing equations for small trees [diameter $<12.7 \mathrm{~cm}$ (Smith, 1985) or diameter $<5 \mathrm{~cm}$ (Alemdag, 1984)]. Multiple-stemmed trees have greater variability in stem diameters than typical shrub species (Hightshoe, 1988) and biomass equations for several shrub species are not applicable, either.

To estimate biomass in these open-grown, multiplestemmed tree species within agricultural settings, more suitable relationships of biomass to measured characteristics need to be developed. Using Russian-olive trees growing in shelterbelts as a case study, we hypothesize that potential predictors for biomass of open-grown Russian-olive trees are diameter of the trunk at the groundline (trunk basal diameter), diameter of the trunk at breast height (trunk DBH), diameter of each stem at the branch bark ridge (stem basal

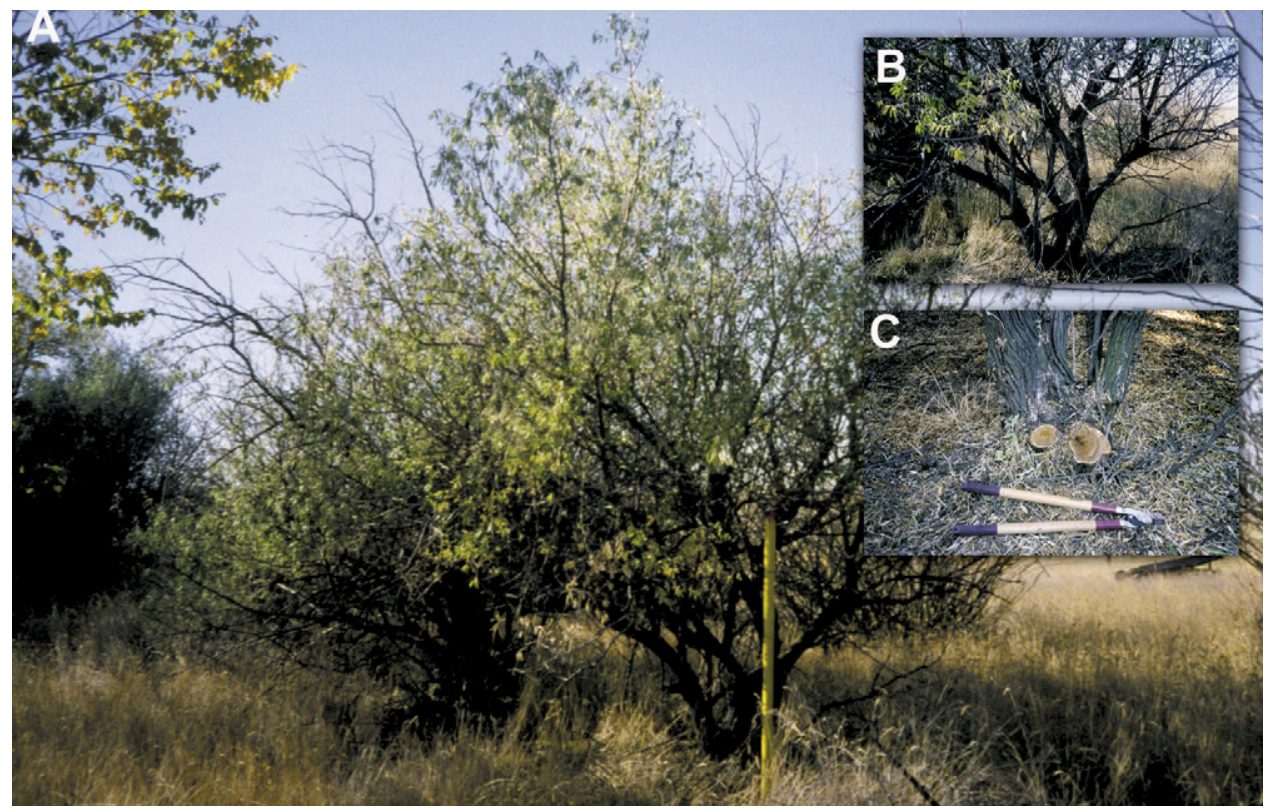

Fig. 1 - A Russian-olive tree under open-grown conditions in Montana, USA (A: crown shape; B: multiple stems; C: stems out of the groundline). 
diameter), diameter of each stem at breast height (stem $\mathrm{DBH}$ ), and tree height. We present a procedure of formulating such a model [biomass function of predictors (independent variables) with undetermined parameters] using chosen predictors and determining an equation (biomass function of predictors with statistically estimated parameters) by optimizing the accuracy in estimates associated with the labor costs, and thereby providing a reference for use with other open-grown, multiple-stemmed tree species (e.g., Prunus Americana Marshall, Malus baccata (L.) Borkh., and E. pungens Thunb.) in agricultural settings.

\section{Data collection}

With the assistance of USDA Natural Resources Conservation Service personnel, 13 shelterbelts containing Russian-olive were identified in nine counties located in the plain regions of eastern Montana, USA during leafless seasons in 2003 and 2004 (Table 1). One plot in each shelterbelt was selected based on uniformity, having a minimum length of $60 \mathrm{~m}$ and including at least 30 Russian-olive trees. In order to standardize terminology, the largest primary stem was designated as the trunk, the larger secondary stems (diameter at the branch bark ridge $>2.5 \mathrm{~cm}$ ) branching out from the trunk below breast height as stems, and all other above-ground woody portions as limbs. For each tree within a plot; trunk basal diameter, trunk DBH, stem basal diameters, and stem $\mathrm{DBH}$ variables were measured to the nearest millimeter. Tree height was measured to the nearest $2.5 \mathrm{~cm}$. Measurements ranged from 2.5 to $33.4 \mathrm{~cm}$ in trunk DBH and from 1.8 to $9.7 \mathrm{~m}$ in tree height. The characteristics of the 13 shelterbelts are summarized in Table 1.

One to three trees from each plot, for a total of 22 trees, were destructively sampled for biomass. These trees ranged from 7.8 to $30.7 \mathrm{~cm}$ in trunk DBH and from 2.5 to $8.9 \mathrm{~m}$ in height. Each sampled tree was marked at breast height on the north side of its trunk and stems, cut at the groundline, and separated into trunk, stems, and limbs. The trunk was immediately weighed to the nearest $0.5 \mathrm{~kg}$ on either a trailer scale system [three Road Weigher (Model: RW Series) scales under a trailer] or a Salter Electrosamson MAN364 scale depending on size. Individual stems and all limbs were similarly weighed.

Each trunk was divided into three sections of equal length (l) and a moisture sample was taken from each section. The middle diameter of each section (d) was measured to the nearest millimeter for calculating the section volume $\left(\pi l d^{2} / 4\right)$ that was used as the statistical weight of moisture content in the section. The same protocol was used for each stem. The limbs were visually grouped into the three basal diameter $\left(d_{0}\right)$ classes: small $\left(d_{0}<1 \mathrm{~cm}\right)$, medium $\left(1 \mathrm{~cm} \leq d_{0} \leq 2 \mathrm{~cm}\right)$, and large $\left(d_{0}>2 \mathrm{~cm}\right)$. From each class, three moisture samples were collected separately from the base, middle, and top sections of limbs. Each moisture sample was sealed in a plastic bag and returned to the laboratory where fresh and oven-dried (in an air-forced oven at $75^{\circ} \mathrm{C}$ to a constant weight) weights were taken for determining moisture content.

The moisture content of each trunk section was weighted by its volume. The three weighted moisture contents of each trunk were then averaged over the whole trunk volume to represent the moisture content of that trunk. The moisture content of a stem was similarly estimated. The moisture con-

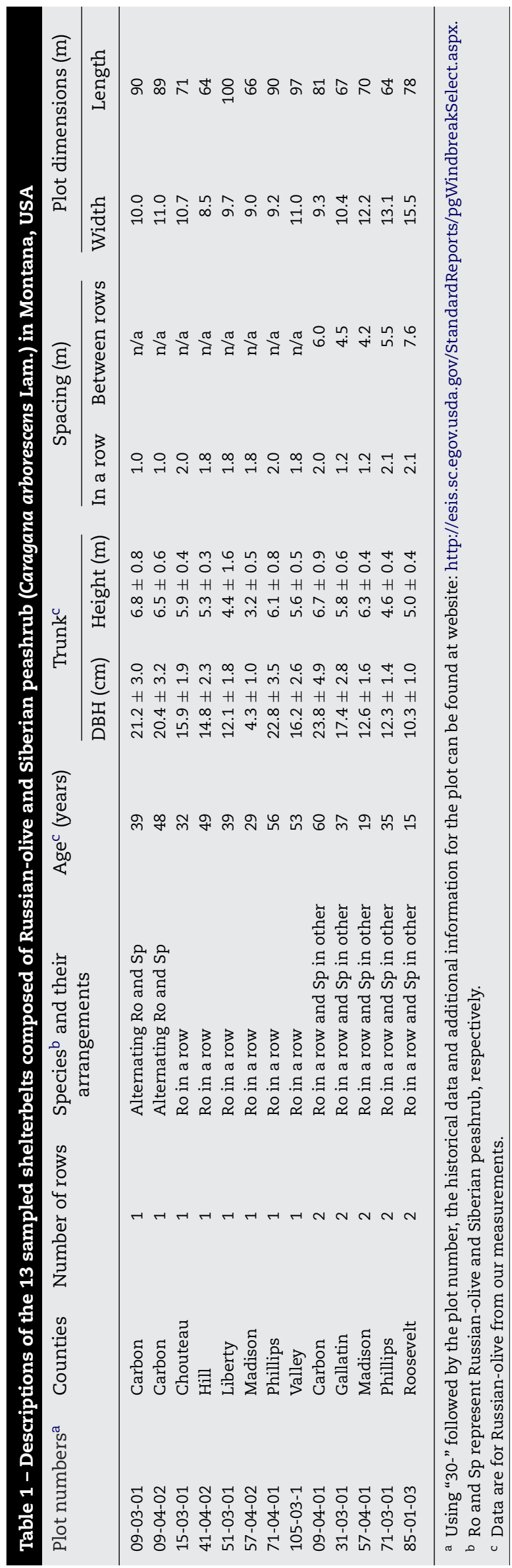


tents of limb samples from the same trees were arithmetically averaged to give a moisture content of all limbs from that tree. The dry weights of the trunk, individual stems, and all limbs were separately determined using their fresh weights and moisture contents.

Two disks were cut from each trunk: (1) between its base and $3 \mathrm{~cm}$ above; (2) between the breast height and $3 \mathrm{~cm}$ above. Two disks were similarly cut from each stem. The trunk base disk was used to determine tree age. The age of an annual ring on a trunk base disk was its sequential order outward from its center. The age of an annual ring on other disks was determined by referencing to the number of annual rings on the trunk base disk. For example, the age of the $n$th ring outward from the center on a stem disk was $n$ plus the difference in the number of annual rings between the stem disk and the trunk base disk. Two diameters of an annual ring were measured to the nearest $0.5 \mathrm{~mm}$ in north-south and east-west directions. The two measurements were averaged to give the diameter at age of the annual ring. All diameters that were measured from a disk for different ages, except for the outermost one, were the diameter inside the bark (DIB).

Since the diameter measured from a standing tree that is used in many biomass equations is the diameter outside the bark (DOB), the measured DIB values for predicting biomass at different ages must be adjusted for bark thickness. This adjustment was done using the linear equation: $\mathrm{DOB}=0.118+1.057 \mathrm{DIB}$ [PVE $=99.8 \%$ where PVE is percentage of variance explained by regression (Mayer and Butler, 1993)] that was developed using data of 98 trunk and stem disks destructively sampled from the trees.

\section{Choosing predictors, formulating models, and determining equations}

Over $92 \%$ of the Russian-olive trees in the 13 plots had multiple stems with three being most common (Fig. 2). Above- ground woody biomass allocation of our sampled trees was $32.2 \pm 6.9 \%$ in trunk, $42.7 \pm 7.6 \%$ in stems, and $25.1 \pm 8.2 \%$ in limbs. However, each stem contained only $9.3 \pm 1.4 \%$ of the total above-ground woody biomass. Although our field measurements were designed to allow the calculation of individual stem biomass, this adds unnecessary details and we combined all stems and limbs into a composite component designated as branches. This component comprised approximately $67.8 \%$ of whole-tree above-ground woody biomass. The equations were developed for the two components: trunk and branches.

A number of potential predictors could be used as independent variables in the biomass models for Russian-olive. For example, a tree with three stems has the nine potential predictors: one height and eight diameters (trunk basal diameter, trunk DBH, three stem basal diameters, and three stem DBH variables). Using these predictors, we can formulate numerous models; however, testing all possible models is impossible. Our approach was to formulate as a simple model as possible and to use as few predictors as possible using ease, reliability, and economics to guide predictor selection and equation determination. Accordingly, predictors must be chosen in sequential order of their importance in determining biomass. The most important predictor is chosen first and used to formulate the simplest model. If this model is inadequate as indicated by PVE, additional predictors are sequentially added and the resulting models are then tested until PVE increases insignificantly and approaches a constant. If different models with the same predictors have equivalent accuracies, the simplest model will be selected for an optimum equation.

\subsection{Trunk}

Potential predictors for trunk biomass are two trunk diameters (basal diameter and DBH) and height. Our hypothesis is that the two trunk diameters are major predictors and height is an auxiliary one, with the two trunk diameters having equivalent ability in

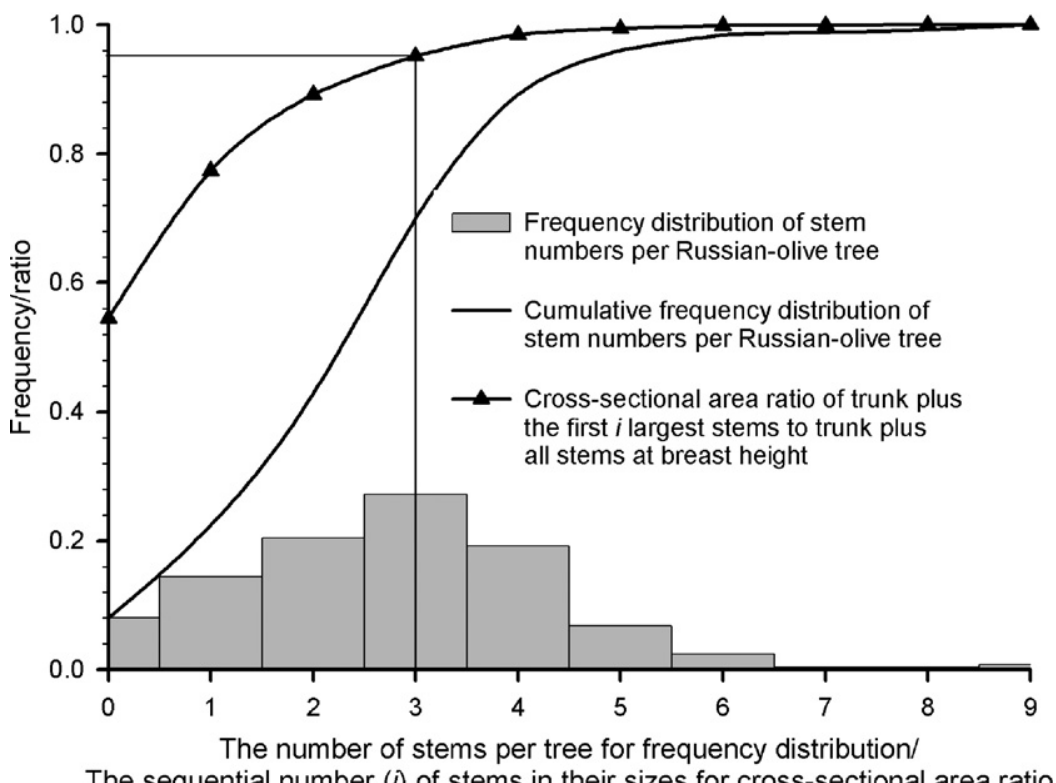

Fig. 2 - Frequency distribution of stem numbers per Russian-olive tree and cross-sectional area ratio of trunk plus the first $i$ largest stems to trunk plus all stems at breast height $(1.37 \mathrm{~m})$ [the data for this figure are summarized from the 13 plots (see Table 1)]. 
Table 2 - Test results of trunk biomass $\left(M_{T}\right)$ and branch biomass $\left(M_{B}\right)$ models using either trunk basal diameter $\left(D_{00}\right)$ or trunk DBH variable $\left(D_{10}\right)$ and/or tree height $(h)$ as predictors

Sequential number Models $^{\mathrm{a}} k=\mathrm{T}$ for trunk $k=\mathrm{B}$ for branches

PVE (\%) percentage of variance explained by regression

\begin{tabular}{|c|c|c|c|}
\hline & & \\
\hline & & Trunk $k=\mathrm{T}$ & Branches $k=\mathrm{B}$ \\
\hline (1) & $M_{k}\left(D_{00}\right)=a_{k 11} D_{0 b^{12}}^{a}$ & $-\mathrm{b}$ & $\# \# \#^{\mathrm{c}}$ \\
\hline (2) & $M_{k}\left(D_{10}\right)=a_{k 21} D_{1}^{a} b_{22}$ & 86.9 & \#\#\# \\
\hline (3) & $M_{k}\left(D_{00}, h\right)=a_{k 31}\left(D_{00}^{2} h\right)^{a_{k 32}}$ & - & 52.9 \\
\hline (4) & $M_{k}\left(D_{10}, h\right)=a_{k 41}\left(D_{10}^{2} h\right)^{a_{k 42}}$ & 90.6 & 38.7 \\
\hline (5) & $M_{k}\left(D_{00}, h\right)=a_{k 51} D_{0852}^{a} h_{k 53}^{a_{k}}$ & - & 53.7 \\
\hline (6) & $M_{k}\left(D_{10}, h\right)=a_{k 61} D_{1}^{a} \delta_{62} h^{a_{k 63}}$ & 90.8 & 39.8 \\
\hline \multicolumn{4}{|c|}{$\begin{array}{l}\text { a } a_{\text {kij }}(k=T \text { or } B, i=1,2,3, \ldots \text {, and } j=1,2,3, \ldots) \text { is a parameter with its first subscript indicating the component of trunk }(\mathrm{T}) \text { or branches }(\mathrm{B}) \text {; its } \\
\text { second, sequential number of the model with this parameter; and its third, a sequential number of the parameter in a model. A random term } \\
\text { is omitted for any model. } \\
\left.\text { b The model was not further considered after analyses of Fig. } 3 \text { due to poor relationship of trunk biomass to trunk basal diameter ( } D_{00}\right) \text {. } \\
\text { c The model was not further considered after analyses of the scatter plots (omitted) of branch biomass against trunk diameters due to obvious } \\
\text { poor relationship of branch biomass to either trunk diameter. }\end{array}$} \\
\hline
\end{tabular}

biomass prediction. Therefore, only one diameter rather than two will be chosen as a predictor for trunk biomass. Height will be added only if necessary. Either diameter more closely related to trunk biomass can be chosen as a major predictor. Accordingly, six potential trunk biomass models using a trunk diameter and/or tree height are listed in Table 2 (Ter-Mikaelian and Korzukhin, 1997). As shown in Fig. 3, trunk biomass is more closely related to the trunk DBH than to the trunk basal diameter. The former, therefore, is chosen as a major predictor. Subsequently, models (1), (3), and (5) in Table 2 that use trunk basal diameter were not further considered for the development of trunk equations. If trunk DBH alone is used, the trunk biomass can be expressed by the simplest model (2) for trunk in Table 2. Using the NLIN procedure of SAS Institute Inc. (1990) (this procedure was used throughout), model (2) was fitted to our data of trunk biomass with a PVE of $86.9 \%$ (Table 2). By including height $(\mathrm{h})$, two additional models were formulated as models (4) and (6) for trunk in Table 2 with resulting PVE values of 90.6 and $90.8 \%$ (see Table 2), respectively. Although PVE values were greater in these two models, model (2) requires only trunk DBH $\left(D_{10}\right)$ and does not have the added cost of measuring height. Moreover, since diameter can be more easily related to age than diameter and height together, model (2) then becomes the preferred model both for age-related predictions and its ability to save labor while still maintaining a satisfactory level of precision.

If greater precision is required, models (4) and (6) for trunk (Table 2) could be used. Although both models use the same two predictors and have nearly the same PVE values, model (6) requires more parameters $\left(a_{\mathrm{T} 61}, a_{\mathrm{T} 62}\right.$, and $\left.a_{\mathrm{T} 63}\right)$. Estimating more parameters uses additional degrees of freedom from the samples, leaving fewer degrees of freedom for standard error estimation (Snedecor and Cochran, 1989). Accordingly, when using model (6) the confidence limits for biomass estimation might be wider than using model (4). The wider the confidence limits are, the greater the relative error in estimation (ratio of the absolute value of confidence limits to estimated mean).

To test this, equations based on models (4) and (6) for trunk (Table 2) were used to estimate the trunk biomass in three plots (09-03-01, 105-03-01, and 85-01-03, see Table 1) that were representative of the sampled shelterbelts in terms of species composition, row arrangement, and diameter range. Thirty trees from each plot were used for this test. As expected, the equation based on model (6) produced wider confidence limits than the other for the same plot. Because the relative error for biomass estimation based on model (4) was at least

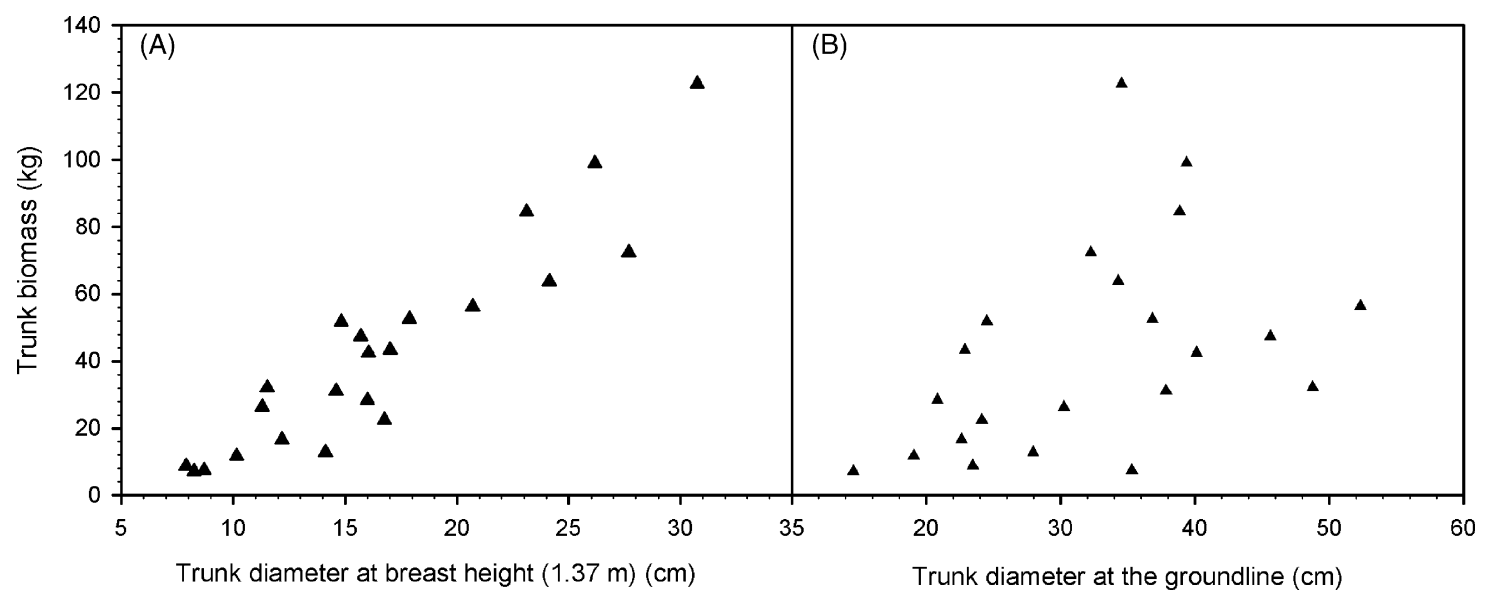

Fig. 3 - Russian-olive trunk biomass against (A) trunk DBH (diameter at height of $1.37 \mathrm{~m}$ ); (B) trunk basal diameter (diameter at the groundline). 
0.5\% smaller, the equation based on model (6) was dropped and the one based on model (4) was adopted for biomass estimation.

\subsection{Branches}

Potential predictors for branch biomass are trunk basal diameter, trunk $\mathrm{DBH}$, individual stem basal diameters, individual stem DBH variables, and tree height. Our hypothesis for branch biomass prediction is that the major predictors are the two trunk diameters with stem diameters and height being auxiliary ones, with the two diameters from the trunk or the same stem having equivalent ability in biomass prediction. Accordingly, a branch model must include one of the two trunk diameters. Stem diameters and/or height may or may not be included depending on their significance in determining branch biomass. If a number of stem diameters are included, these are all measured at a consistent height.

Since, the two trunk diameters along with tree height are the most commonly used predictors for branch biomass (TerMikaelian and Korzukhin, 1997; Chojnacky and Rogers, 1999), the adequacy of models using one or two of these three predictors needs to be tested first. If these models with trunk diameter alone and trunk diameter with tree height prove to be inadequate as indicated by PVE, stem diameters are then incorporated into the models with trunk diameter and tested again. If the prediction using a combination of trunk diameter with stem diameters is improved, tree height would then be used again and ancillary to this combination for final testing.

\subsubsection{Branch models using a trunk diameter and/or tree height}

Using the same procedures as described for developing trunk equations, six potential branch biomass models using a trunk diameter and/or tree height are listed in Table 2. Similar to the development of Fig. 3, we plotted branch biomass against trunk basal diameter and trunk $\mathrm{DBH}$, respectively. In both cases (figures omitted), data were widely scattered, indicating that neither diameter alone could satisfactorily predict branch biomass. Further, the value of adding tree height to a branch biomass model to predict biomass can be assessed using branch models (3) to (6) in Table 2. The maximum PVE of all four models was only $53.7 \%$ (see Table 2 ), indicating a need to also include individual stem diameters as potential predictors.

\subsubsection{Branch models using trunk diameter and stem diameters}

The maximum number of stems including trunk for the Russian-olive trees observed in our plots was 10 (Fig. 2). If trunk diameter and individual stem diameters are considered separately in a model, the number of parameters needed increases as does the number of samples required for their estimation. For example, the simplest linear branch biomass $\left(M_{B}\right)$ model that can separately describe the determination of these diameters in branch biomass is given by

$\mathrm{M}_{\mathrm{B}}=\sum_{j=0}^{10} a_{\mathrm{Bj}} \mathrm{D}_{1 j}$ where $a_{\mathrm{Bj}}$ is a parameter and $D_{1 j}$ is a $\mathrm{DBH}$ variable. Subscript $B$ indicates the branch component; subscript $j=0$, trunk and $j=1,2, \ldots, 10$, the sequential number of stems in diameter size. The random error term is omitted in this model and also in other models throughout this paper. This model, including 11 diameters (one trunk DBH and 10 stem DBH variables) as predictors, uses 11 parameters $\left(a_{\mathrm{Bj}}\right)$ to describe the separate contributions of the diameters to determination in branch biomass. As the complexity of the branch model grows, the tradeoffs between greater precision and escalating costs related to increased sampling requirement need to be considered. Alternatively, by combining trunk diameter and stem diameters as one independent variable in a model, the number of parameters needed can be minimized.

The implications of combining trunk diameter and stem diameters as an arithmetical sum, however, are less clear. The sum of these diameters squared is linearly proportional to the cross-sectional area of the trunk and stems that is a well-known predictor of biomass (Chiba, 1998). Assuming the diameter of a larger stem contributes more than the diameter of a smaller stem in determination of branch biomass, combining trunk diameter with diameters of several of the largest stems could provide a better estimate of branch biomass. Thus, we considered the following model:

$M_{B}=a_{B 71}\left(\sum_{j=0}^{n} D_{i j}^{2}\right)^{a_{B 72}}$

where $a_{\mathrm{Bij}}$ is a parameter (the first subscript $\mathrm{B}$ indicates the branch component; the second subscript $i$, the sequential number of the model with this parameter; the third subscript $j$, the sequential number of the parameter in this model); $D_{i j}$, diameter (the first subscript $i=0$ or 1 indicates basal diameter or $\mathrm{DBH}$ and the second subscript $j=0$ or $>0$ indicates trunk or the sequential number of stems in diameter size); and $n=0$, $1,2, \ldots$, the number of stems. This model expresses branch biomass as an exponential function of a combined variable: the sum of trunk diameter squared and the first $n$ largest stem diameters squared. According to our hypothesis for testing the relationship of branch biomass to diameters and height, we considered the four major combinations of subscripts $i$ and $j$ for diameter variables in model (7): (1) $i=0$ for any $j$ (all basal diameters); (2) $i=1$ for any $j$ (all DBH variables); (3) $i=0$ for $j=0$ and $i=1$ for $j>0$ (trunk basal diameter and stem $\mathrm{DBH}$ variables); (4) $i=1$ for $j=0$ and $i=0$ for $j>0$ (trunk DBH and stem basal diameters). Given that the maximum number of stems in the 22 destructively sampled trees was six $(n=6)$, there were 28 models derived from model (7) for our consideration. The 28 models were fitted to our data and their PVE values were plotted against the number of stems in Fig. 4.

The PVE values of the models using trunk basal diameter along with stem basal diameters or stem $\mathrm{DBH}$ variables were less than $56.6 \%$ (Fig. 4, lower two curves). In contrast, using trunk DBH along with stem basal diameters or stem DBH variables gave higher PVE values (Fig. 4, upper two curves). The PVE was $79.9 \%$ for trunk DBH and the first three largest stem basal diameters and $74.8 \%$ for trunk DBH and the DBH variables of the first three largest stems. In both cases, adding additional stem diameters provided little increase in PVE values. 


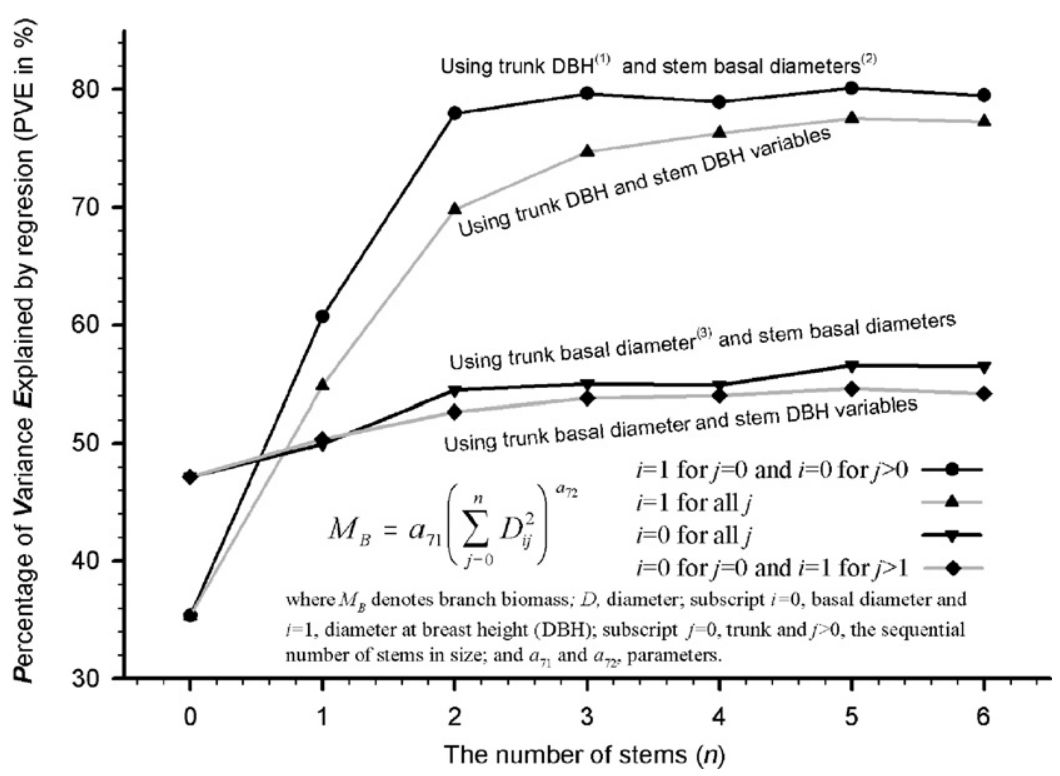

Fig. 4 - Percentages of variance explained by regression for Russian-olive branch biomass $\left(M_{B}\right)$ equations using a trunk diameter along with the first $n$ largest stem diameters [(1) diameter at breast height $(1.37 \mathrm{~m})$; $(2)$ diameter of a stem at branch bark ridge; (3) diameter at the groundline].

The top curve in Fig. 2 shows that in the sum of the trunk and stem diameters squared, $95.2 \%$ of the sum came from trunk plus the first three largest stems and only $4.8 \%$ from additional stems. This sum from the additional stems was relatively small and considered negligible, being contributed by only $30 \%$ of the trees (Fig. 2). Therefore, using trunk DBH plus the three largest stem basal diameters and trunk DBH plus the three largest stem DBH variables are two reasonable approaches to the development of branch equations. Although the former approach gave PVE values greater than the latter (Fig. 4), it costs more because measuring the needed stem basal diameters is less convenient than measuring stem DBH. Considering that there were pros and cons with going with either approach, we chose to keep both for further assessments that include height.

\subsubsection{Incorporating height into branch models using} trunk $\mathrm{DBH}$ and stem diameters

Analogous to trunk models (3) to (6) (see Table 2), tree height was incorporated into model (7) to see if it improved branch biomass estimation. The height-incorporated models were tested as described earlier for trunk models (4) and (6). Using the same diameters, PVE values for the height-incorporated models were slightly greater $(0.5 \%)$ or lower $(2.7 \%)$ than the values for the corresponding models derived from the original model (7). Since the assessment of the height-incorporated models with greater PVE values did not show improvement of plot estimation by reducing relative errors, tree height was not included in the final branch models.

\section{Application of the developed equations}

Using the procedure described above, a pair of equations was developed for each of the two components: trunk and branches (see Table 3). In each pair, one equation requires DBH variables only (trunk DBH for trunk or DBH variables of trunk and the three largest stems for branches) and the other requires an additional predictor (height for trunk) or less conveniently measured variables (stem basal diameters for branches). The tradeoff between the two equations is having one which uses easily measured predictors but has a relatively lower PVE value while the other with a higher PVE value has an additional cost incurred by the extra and inconvenient measurements required. The greater PVE an equation has statistically, the better precision its estimates potentially have (Mayer and Butler, 1993). Accordingly, the equation with greater PVE in each pair is classified as a precision-preferred (PP) equation and the other as a cost-saving-preferred (CSP) equation (Table 3). In each of the two classes, there are two equations for trunk and branches, respectively, forming a set of equations for whole tree. The equations can be used to estimate the biomass of existing shelterbelts and to predict the biomass of a shelterbelt at different ages.

\subsection{Estimating the biomass of existing shelterbelts}

As examples, the data from the three plots that were used to compare trunk model (4) to trunk model (6) in Table 2 in Section 3.1 were also used to estimate the biomass of the three shelterbelts. Substituting the plot data into each set of equations in Table 3, values for the three plots were estimated for trunk, branches, and whole tree in kilograms per 100-m length (Table 4). Within a plot, the PP equations consistently gave better precision (narrower 95\% confidence limits) for each component estimate than the CSP equations. However, relative errors in whole-tree biomass estimated using the PP equations were only $0.8-1.2 \%$ lower than those using the CSP equations. 
Table 3 - Above-ground woody biomass equations for individual Russian-olive trees grown in shelterbelts in Montana, USA

\begin{tabular}{|c|c|c|c|c|}
\hline & \multicolumn{2}{|c|}{ Trunk biomass, $\mathrm{M}_{\mathrm{T}}(\mathrm{kg})$} & \multicolumn{2}{|c|}{ Branch biomass, $M_{B}(\mathrm{~kg})$} \\
\hline Ranges in diameter and height & $7 \leq D_{10} \leq 31 \mathrm{~cm}, 3 \leq h$ & & $180 \leq D_{10}^{2}+\sum_{j=1} D_{c}^{2}$ & $2_{1 j} \leq 1100 \mathrm{~cm}^{2}$ \\
\hline Precision-preferred & $M_{\mathrm{T}}=0.1368\left(D_{10}^{2} h\right)^{0.7559}$ & PVE $90.6 \%$ & $M_{B}=6.572 \times 10^{-3}$ & PVE $79.7 \%$ \\
\hline Cost-saving-preferred & $\mathrm{M}_{\mathrm{T}}=0.3019 D_{10}^{1.733}$ & PVE $86.9 \%$ & $M_{B}=5.067 \times 10^{-2}$ & PVE $74.7 \%$ \\
\hline
\end{tabular}

$D_{10}(\mathrm{~cm})$ is diameter of trunk at breast height $(1.37 \mathrm{~m}) ; D_{i j}(\mathrm{~cm}), j>0$, diameter of the $j$ th largest stem at branch bark ridge $(i=0)$ or at breast height $(i=1) ; h(m)$, height; PVE, percentage of variance explained by regression.

As indicated by the $95 \%$ confident limits or relative error in Table 4, the precision of biomass estimated using the same equation for any component varied by shelterbelt. This was expected as the precision of a biomass equation varies with different values of diameters and/or tree height (Bates and Watts, 1988) and the ranges of tree sizes in the three plots were very different (Table 1). Since this precision at a given diameter and tree height is determined by the number of trees measured (Snedecor and Cochran, 1989), measuring more trees will increase precision (narrows the $95 \%$ confident limits and reduces the relative error), but will require more labor. This warrants calculating the minimum number of trees needed to attain a certain level of precision prior to going to the field; this calculation being based on the desired relative error, diameters, and heights. The desired relative error is given by the precision requirement for estimation. As it is relatively easier to obtain information on the range in trunk DBH values than for individual trunk diameters, stem diameters, and heights, we developed the figures (Fig. 5A and B) for both sets of equations that can be used to approximate the number of trees needed for field measurements based on the range of trunk DBH values and the desired relative error of whole-tree biomass.

The figures were developed by again running the NLIN procedure of SAS Institute Inc. (1990) for each equation in Table 3 using the data from the destructively sampled trees, followed by data from the 13 plots (Table 1 ). The resulting component biomass estimates along with their variances were averaged for each of the five ranges of trunk DBH values: 9-11, 14-16, 19-21, 24-26, and 29-31 cm, representing the median values of $10,15,20,25$, or $30 \mathrm{~cm}$ for the five ranges, respectively. The formula of Snedecor and Cochran (1989) for sample size was then used to develop the relationship between the relative error in whole-tree biomass estimates and the number of measured trees (Fig. 5). For example, if the relative error is given to be less than $5 \%$ for a whole-tree biomass estimate using the CSP equations for trees over a trunk DBH range of $20-25 \mathrm{~cm}$, this number is 65 (see Fig. 5B). If the curves in Fig. 5 are not available for a range of trunk DBH in the shelterbelt to be measured, this number can be interpolated between the curves.

\subsection{Predicting the shelterbelt biomass at different ages}

For predicting the biomass of a shelterbelt at different ages, the diameters and height in the equations in Table 3 need to be related to age using field data. Since the PP equations reduced the relative error by such a small value $(0.8-1.2 \%$ for whole-tree biomass, see Table 4) and require additional costs related to height measurements, which by themselves brings in greater variability with age, only the CSP equations were used for the

Table 4 - Above-ground woody biomass of Russian-olive shelterbelts (mean $\pm 95 \%$ confidence limit ${ }^{\text {a }}$ in kilograms per 100-m length)

\begin{tabular}{|c|c|c|c|c|c|c|c|c|}
\hline \multirow[t]{2}{*}{ Plot number ${ }^{b}$} & \multicolumn{4}{|c|}{ Cost-saving-preferred equations (CSP) } & \multicolumn{4}{|c|}{ Precision-preferred equations (PP) } \\
\hline & Trunk & Branch & Whole tree & $\mathrm{RE}^{\mathrm{c}}(\%)$ & Trunk & Branch & Whole tree & $\mathrm{RE}(\%)$ \\
\hline 09-03-01 & $1938 \pm 159$ & $3019 \pm 385$ & $4957 \pm 417$ & 8.4 & $1905 \pm 139$ & $2994 \pm 336$ & $4898 \pm 363$ & 7.4 \\
\hline $105-03-1$ & $1173 \pm 142$ & $2463 \pm 361$ & $3636 \pm 388$ & 10.7 & $1121 \pm 121$ & $2408 \pm 312$ & $3529 \pm 334$ & 9.5 \\
\hline $85-01-03$ & $667 \pm 173$ & $1208 \pm 425$ & $1875 \pm 458$ & 24.5 & $601 \pm 147$ & $1143 \pm 386$ & $1744 \pm 413$ & 23.7 \\
\hline
\end{tabular}

a The $95 \%$ confidence limits were calculated based on the standard deviations of individual tree biomass estimates that were outputted from the NLIN procedure of SAS Institute Inc. (1990).

b Using the plot numbers, the characteristics of the three shelterbelts can be found in Table 1.

${ }^{c} \mathrm{RE}$ is relative error in a whole-tree biomass estimate. 
age-related biomass prediction. Accordingly, trunk DBH alone and the sum of the trunk and three largest stem $\mathrm{DBH}$ variables squared need to be separately related to age.

The shelterbelt represented by plot 71-04-01 (see Table 1) was 56 years old and had annual diameter data collected from three harvested trees. For the three trees, the average trunk DBH was $24.6 \mathrm{~cm}$ and the average sum of the trunk and three largest stem DBH variables squared was $970 \mathrm{~cm}^{2}$. The average trunk DBH was representative of the shelterbelt (see Table 1). Therefore, the data from these three trees were used to predict the biomass of the shelterbelt at different ages. Both averages from the three trees at different ages were separately substituted into the CSP equations to give the biomass of trunk and branches at ages from 10 to 56. Using these data, the above-ground woody biomass values of a one-row, 2-m-spacing Russian-olive tree shelterbelt with different survival rates were plotted against age in Fig. 6 . For example, the biomass of this type shelterbelt at age of 50 is between 7.8 and 8.7 metric tonnes per 100 - $\mathrm{m}$ length for a survival rate between 85 and $95 \%$.

\section{Discussions}

\subsection{Applicability of reported models to open-grown, multiple-stemmed tree species}

Biomass models for the species of single-stemmed trees, understory multiple-stemmed trees, and shrubs were a valuable source for our study as those for open-grown, multiple-stemmed tree species in literature are very limited to non-existent. The models for single-stemmed trees using trunk DBH and/or height as predictors as per TerMikaelian and Korzukhin (1997) work well for trunk but not for branches in our study trees (see Table 2). However, in these trees, trunk biomass comprises only a minor portion (32\%) of the total above-ground woody biomass as compared to the branch biomass (68\%). The accuracy of the branch estimates any equation will therefore greatly influence the accuracy of the overall above-ground biomass estimates for these species.

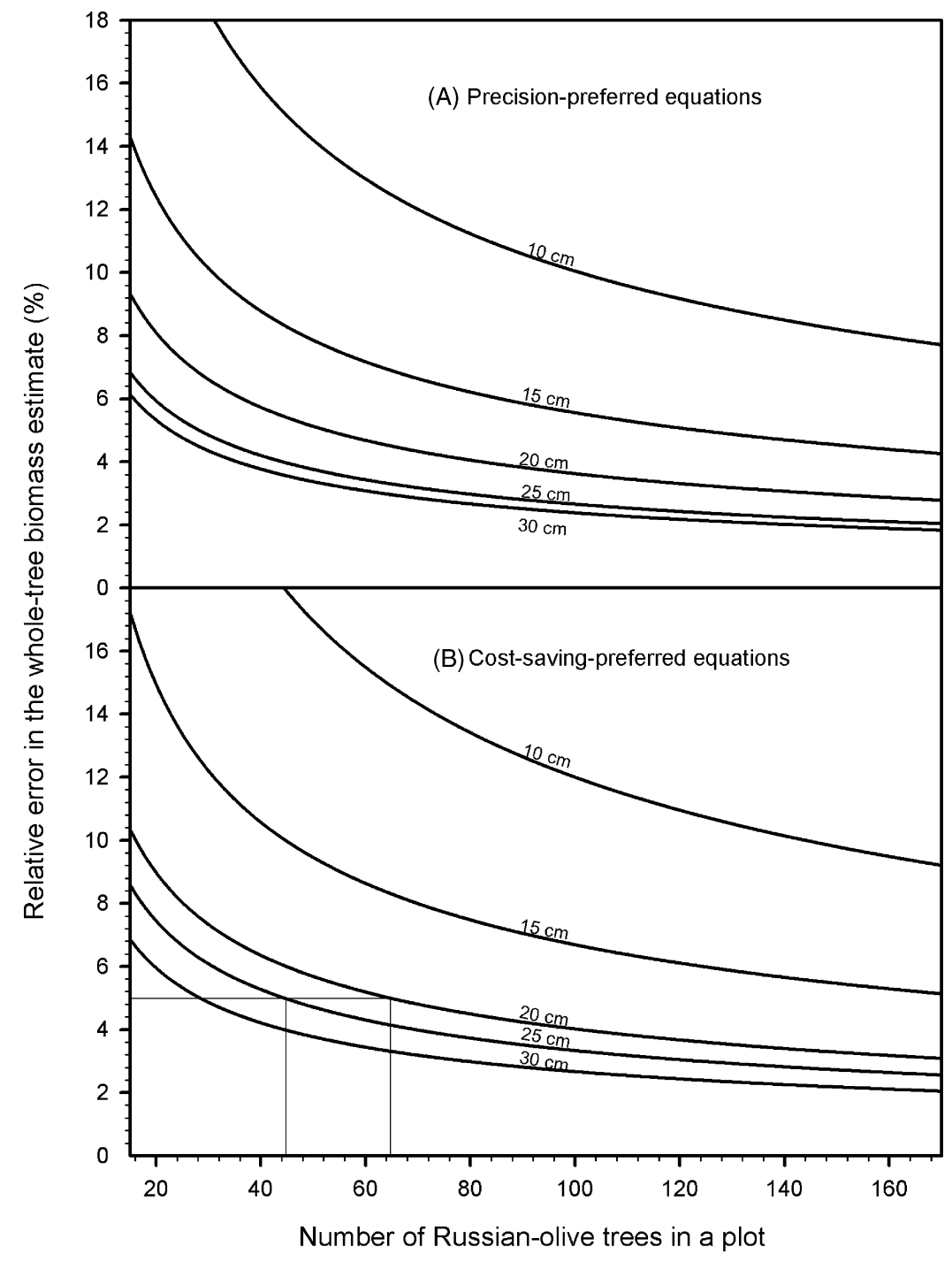

Fig. 5 - Relative errors in a whole-tree biomass estimate for the five trunk DBH values of $10,15,20,25$, and $30 \mathrm{~cm}$ against the number of Russian-olive trees to be measured in a plot when (A) precession-preferred equations or (B) cost-saving-preferred equations are used. 


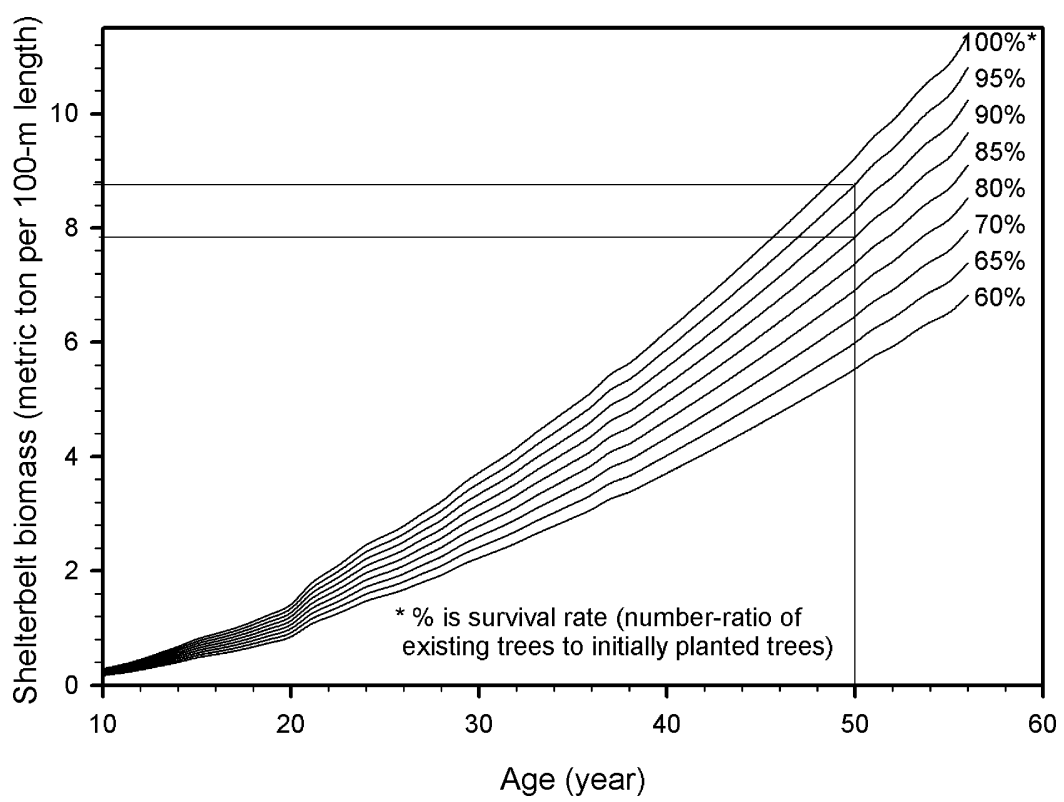

Fig. 6 - Above-ground woody biomass of a single-row Russian-olive shelterbelt at different ages in Philips County, Montana, USA (spacing in a row is $\mathbf{2} \mathbf{m}$ and soil is Telstad-Joplin loam).

The biomass models of understory multiple-stemmed tree species that use trunk basal diameter (Chojnacky and Rogers, 1999), DBH (Roussopoulos and Loomis, 1979), or trunk diameter at other heights (Grigal and Ohmann, 1977) are essentially similar to those in Table 2 for single-stemmed tree species but fail to satisfactorily fit to our data for Russian-olive. In open-grown, multiple-stemmed species, the individual stems are generally smaller and have less biomass than its main trunk, but not as much as the stems of undersory multiplestemmed trees. As a result, trunk diameter alone may not be able to explain branch biomass in our study species as well as in understory multiple-stemmed tree species. Accordingly, we also assert that trunk diameter alone at other heights would not be a good predictor, either.

The biomass models of shrub species mostly use crown diameter (Ohmann et al., 1976), shrub height, crown volume, stem number (Peek, 1970), or crown percent cover (Ohmann et al., 1981). The dependence of branch biomass on crown dimensions (crown diameter, tree height, and crown volume) was preliminarily tested using the data of 13 trees measured in 2003, but results were insignificant. As discussed in the introduction, an open-grown, multiple-stemmed tree generally has the greater variability in stem diameter than a typical shrub. The biomass in its crown may not distribute spatially as uniform as in a canopy of a shrub and its crown dimensions may not have as good relationship to branch biomass as to the shrub crown dimensions. Crown dimensions along with a trunk diameter could be an alternative, although measuring all of the related variables is labor intensive and may not be economically feasible. In the case of Russian-olive, as with many of the other multiple-stemmed tree species used in windbreaks, the trees soon become taller than human height. This height, along with the multiple stems in the lower portion of the plant, makes it extremely difficult to measure crown percent cover in these species. It was for these reasons that we did not include shrub biomass models using crown percent cover or test crown percent cover in our biomass predictions.

Apparently, none of the above models used a predictor that would clearly explain the branch biomass in an open-grown, multiple-stemmed tree species. The success of developing branch equations for these tree species depends on using one or more predictors that better explain the branch biomass. Our branch equations were determined by comparing the 34 models (six in Table 2 and 28 in Fig. 4) in terms of optimizing the accuracy in estimates associated with labor costs. In the branch equations we then selected (Table 3), the predictor is a composite predictor (sum of trunk DBH squared plus three largest stem diameters separately squared). Based on this predictor, our branch equations work reasonably better for the tree species in this study. Representing $95.2 \%$ of the cross-sectional area of trunk and stem components supporting all branches (Fig. 2), this predictor works well to explain branch biomass because "the plant weight above a given position is in proportion to the stem cross-sectional area at that position" (Chiba, 1998).

\subsection{Equations, models, and procedure}

Our equations were developed using the data from 22 destructively sampled Russian-olive trees. Apparently, the sample size was insufficient for the development of more widely applicable equations. For wider application and greater accuracy, these equations will need to be calibrated using data from more destructively sampled Russian-olive trees over a larger geographical area. This is particularly true for small size trees (trunk $\mathrm{DBH}<10 \mathrm{~cm}$ ) if the number of trees measured for biomass estimation is inadequate (Fig. 5). This low accuracy is a result of the insufficient number of our destructively sampled trees for biomass and by the relatively low precision of the equations in this range of trunk $\mathrm{DBH}$. 
Even though the developed equations have limited applicability in other regions, the models from which the equations were developed and the procedure through which the equations were determined provide a reference to development of biomass equations for other open-grown, multiple-stemmed tree species in agricultural settings. Equations in Table 3 were developed using trunk DBH and three largest stem diameters. The use of three stem diameters may prove inadequate or excessive for use with other multiple-stemmed species. We designated the stem number ( $n$ ) in model (7) as a variable rather than a constant in order to provide flexibility in accommodating other open-grown, multiple-stemmed tree species. The procedure is a reasoning process of choosing predictors that are easy to measure and likely to have good relationship to biomass, formulating models that may potentially be used for biomass equations, and determining equations that optimize a balance of accuracy and labor costs. This procedure can be followed for other open-grown, multiple-stemmed tree species.

\subsection{Trunk basal diameter and trunk DBH for biomass prediction}

Although we hypothesized that trunk basal diameter and DBH would have the same degree of significant relationship to biomass, Figs. 3 and 4 show this is not the case. Since diameter is derived from field-measured circumference, this lack of significant relationship between trunk basal diameter and biomass may be due to the greater irregularity of trunk circumference at groundline than at breast height; thereby producing a less representative measure of the average diameter within the circumference.

The inconsistency between our hypothesis and the data in Fig. 4 may also be due in part to trunk basal diameter squared being a much larger value than trunk DBH squared, in this case resulting in a ratio of 3.0. Likewise, the ratio of the average trunk basal diameter squared to the average sum of stem basal diameters squared is 3.0 and to the average sum of stem $\mathrm{DBH}$ variables squared is 5.2 indicating that trunk basal diameter squared dominates the diameters squared in model (7). Because the two parameters $\left(a_{\mathrm{B} 71}\right.$ and $\left.a_{\mathrm{B} 72}\right)$ in model (7) describe the determinations of trunk diameter and stem diameters together in biomass, this dominance may distort the relationship of stem diameters to branch biomass.

As such, possible branch biomass models able to separate the determination of trunk basal diameter from stem diameters in branch biomass are given by

$M_{\mathrm{B}}=a_{\mathrm{B} 81} D_{00}^{a_{\mathrm{B} 82}}\left(\sum_{j=1}^{n} D_{\mathrm{ij}}^{2}\right)^{a_{\mathrm{B} 83}}$

and

$\mathrm{M}_{\mathrm{B}}=a_{\mathrm{B} 91} D_{00}^{a_{\mathrm{B} 92}}+a_{\mathrm{B} 93}\left(\sum_{j=1}^{n} D_{i j}^{2}\right)^{a_{\mathrm{B} 94}}$

where the two parameters: $a_{\mathrm{Bi} 1}$ and $a_{\mathrm{Bi} 2}(i=8$ or 9 ) describe the determination of trunk basal diameter in branch biomass and the parameters: $a_{\mathrm{Bi} 3}$ and/or $a_{\mathrm{Bi} 4}$ describe the determination of stem diameters in branch biomass. To evaluate these models, the PVE of all 36 models that can be generated from models (8) and (9) [For $i=0$ or 1 and $n=1,2, \ldots$, or 6, 12 models from model (8) and 12 models from model (9); and for $a_{\mathrm{B} 93}=1$ or $a_{\mathrm{B} 94}=1$, model (9) generates additional 12 models] were examined. The maximum PVE was $61.4 \%$ which was greater than those calculated for model (7) using trunk basal diameter plus stem diameters (Fig. 4). This indicates that the determination of stem diameters in branch biomass in model (7) was distorted by trunk basal diameter. Nonetheless, PVE values of models (8) and (9) are still much smaller than those of the models from which the branch equations in Table 3 were developed, indicating a less significant relationship of trunk basal diameter to branch biomass than trunk DBH. The less significant relationship, although less supportive to our hypothesis, does not invalidate our equations as the validity of the hypothesis is based on most of the trees (Chojnacky and Rogers, 1999) and was therefore used to reasonably initiate the equation development in this study.

\subsection{Additional error from use of branch equations}

Our branch equations use trunk $\mathrm{DBH}$ and the three largest stem diameters. If a tree has more than three stems similar in size, the three largest stems may be incorrectly identified based on visualization in the field, causing an additional error in biomass estimates beyond equation precision. This error should be negligible if the stems are similar in their sizes. While only $30 \%$ of the trees in our samples had more than three stems (Fig. 2), the maximum of this error (using the forth largest diameter instead of the third largest one) was estimated using the branch equations in two ways: (1) by substituting trunk DBH and up-to-three largest stem diameters into the equations; (2) by substituting trunk $\mathrm{DBH}$, up-to-two largest stem diameters, and the fourth largest stem diameter, if any, into the equations. Relative to the plot branch biomass estimated normally, the maximum error in plot branch biomass estimated in the second way was $1.2 \%$, contributing $0.8 \%$ of the relative error in plot whole-tree biomass. Given the low occurrence that the third largest stem is confused with the fourth one for all trees in a plot, this relative error should be negligible.

\section{Summary and conclusion}

Discussions have been initiated on how agroforestry and other tree-based buffer plantings might be incorporated into carbon accounting tools for agricultural lands, such as COMET VR (USDA NRCS, 2005) and C-Lock (Zimmerman et al., 2005). Modeling efforts, such as SEEDSCAPE, are trying to predict growth and succession of woody plant species under different climate and management scenarios (Easterling et al., 2001; Guo et al., 2004). Both types of efforts require biomass equations that can accurately reflect these species under the more open-grown conditions in these agricultural settings. The effort reported here presents a procedure for developing equations that 
can more accurately estimate biomass of the open-grown, multiple-stemmed tree species currently used in these plantings. Using destructively and non-destructively sampled data from 13 shelterbelts, we determined that trunk DBH and/or height were satisfactory for trunk biomass prediction in Russian-olive, but insufficient to determine branch biomass because of its greater variability at a given diameter and/or height. Incorporating the diameters of several of the largest stems into the models improved branch biomass prediction satisfactorily.

The procedure produced two sets of equations: costsaving-preferred (CSP) and precision-preferred (PP) (see Table 3). Each set includes two equations for trunk and branches, respectively. The CSP equations use only conveniently measured $\mathrm{DBH}$ variables of trunk and stems as predictors; requiring less labor and cost but having little lower precision than PP equations. The PP equations have better precision than CSP, but require labor and costs for the additional predictor of tree height and less convenient measurements of stem basal diameters. While the PP equations consistently gave better precision (narrower 95\% confidence limits and smaller relative error) in estimating biomass in representative shelterbelts (Table 4), the relative errors in whole-tree biomass were only slightly lower (0.8-1.2\%) than those using the CSP equations. The extra cost associated with the PP equations may not therefore be justified. The CSP equations also have the advantage of being more easily used to predict the biomass at different ages (Fig. 6). Ultimately, which set of equations will be used depends on the desired accuracy and/or available budget.

Although the specific application of the equations developed in this research is limited to open-grown Russian-olive trees in Montana, the models and procedure for these equations have valuable applications to other open-grown, multiple-stemmed tree species. Using the procedure laid out for shelterbelt-grown Russian-olive trees, equations and predictors can be modified accordingly for application with other open-grown, multiple-stemmed tree species in agricultural settings.

\section{Acknowledgments}

A contribution of the University of Nebraska Agriculture Research Division, Lincoln, Nebraska, USA. This research was supported in part by funds provided through USDA/CSRS NRI Competitive Grants (\# 2001-35108-10205), USDA Forest Service, Rocky Mountain Research Station (Agreement nos.: JV-11221604-142 and JV-11221604-143), and the McIntireStennis Forestry Research Program. Thanks to K.A. and C.L. Messenger for their field work; USDA NRCS personnel (R. Logar, G. Evertz, G. Hill, S. Lomax, D. Grabofsky, B. Albee, K. Whipple, D. Wickum, M. Thompson, T. Beck, R. Bray, T. Israel, and D. Wiedenheft); US Corps of Engineers personnel (P. Gilbert) for their assistance with site selection and field work; and the very gracious landowners (M. Brastrup, L. Hart, T. and R. DeBorde, M. Fukkema, D. and S. Velk, J. England, J. and J. Anderson, J. Tilstra, D. and R. Grabofsky, and J. and L. Beck) who permitted us access to their shelterbelts.

\section{REFERENCES}

Alemdag, I.S., 1984. Total tree and merchantable stem biomass equations for Ontario hardwoods. Canadian Forestry Service, Petawawa National Forestry Institute, Information Report PI-X-46, 54 pp.

Bagley, W.T., Sutton, R.K., 2002. Woody Plants for the Central and Northern Prairies. Blackburn Press, Caldwell, New Jersey, 604 pp.

Bates, D.M., Watts, D.G., 1988. Nonlinear Regression Analysis and its Applications. John Wiley \& Sons, New York, 365 pp.

Brand, G.J., Smith, W.B., 1985. Evaluating allometric shrub biomass equations fit to generated data. Can. J. Bot. 63, 64-67.

Brown, J.K., 1976. Estimating shrub biomass from basal stem diameters. Can. J. For. Res. 6, 153-158.

Chiba, Y., 1998. Architectural analysis of relationship between biomass and basal area based on pipe model theory. Ecol. Model. 108, 215-219.

Chojnacky, D.C., Rogers, P., 1999. Converting tree diameter measured at root collar to diameter at breast height. Western J. Appl. For. 14, 14-16.

Cunningham, R.A., 1988. Genetic improvement of trees and shrubs used in windbreaks. Agric. Ecosyst. Environ. 22/23, 483-498.

Dirr, M.A., 1983. Manual of Woody Landscape Plants: Their Identification, Ornamental Characteristics, Culture, Propagation and Uses, 3rd ed. Stipes Publishing Company, Champaign, Illinois, $826 \mathrm{pp}$.

Easterling, W.E., Brandle, J.R., Hays, C.J., Guo, Q.F., Guertin, D.S., 2001. Simulating the impact of human land use change on forest composition in the Great Plains agroecosystems with the SEEDCAPE model. Ecol. Model. 140, 163-176.

Grigal, D.F., Ohmann, L.F. 1977. Biomass estimation for some shrubs from northeastern Minnesota. USDA Forest Service, Research Notes NC-226, 3 pp.

Guo, Q.F., 2000. Climate change and biodiversity conservation in Great Plains agroecosystems. Global Environ. Change 10, 289-298.

Guo, Q.F., Brandle, J., Schoeneberger, M., Buettner, D., 2004 Simulating the dynamics of linear forests in Great Plains agroecosystems under changing climates. Can. J. For. Res. 34, 2564-2572.

Hightshoe, G.L., 1988. Native Trees, Shrubs, and Vines for Urban and Rural America: A Planing Design Manual for Environmental Designers. Van Nostrand Reinhold, New York, 819 pp.

Mayer, D.G., Butler, D.G., 1993. Statistical validation. Ecol. Model. $68,21-32$.

Montagnini, F., Nair, P.K.R., 2004. Carbon sequestration: an underexploited environmental benefit of agroforestry systems. Agrofor. Syst. 61, 281-295.

Nicholas, I.D., 1988. Plantings in tropical and subtropical areas. Agric. Ecosyst. Environ. 22/23, 465-482.

Ohmann, L.F., Grigal, D.F., Brander, R.B., 1976. Biomass estimation for five shrubs from Northeastern Minnesota. USDA Forest Service, Research Paper NC-133, 11 pp.

Ohmann, L.F., Grigal, D.F., Rogers, L.L., 1981. Estimating plant biomass for undergrowth species of Northeastern Minnesota forest communities. USDA Forest Service, General Technical Report NC-61, 10 pp.

Peek, J.M., 1970. Relation of canopy area and volume to production of three woody species. Ecology 51, 1098-1101.

Roussopoulos, P.J., Loomis, R.M., 1979. Weights and dimensional properties of shrubs and small trees of the Great Lakes conifer forest. USDA Forest Service, Research Paper, NC-178, 6 pp.

SAS Institute Inc., 1990. The NLIN procedure. In: SAS/STAT ${ }^{\circledR}$ User's Guide, Version 6, SAS Institute Inc., Gary, North Carolina, pp. 1135-1194. 
Smith, B.W., 1985. Factors and equations to estimate forest biomass in the North Central Region. USDA Forest Service, Research Paper NC-268, 6 pp.

Snedecor, G.W., Cochran, W.G., 1989. Statistical Methods, 8th ed. Iowa State University Press, Ames, Iowa, 503 pp.

Stannard, M., Ogle, D., Holzworth, L., Scianna, J., Sunleaf, E., 2002. History, biology, ecology, suppression and revegetation of Russian-olive sites (Elaeagnus angustifolia L.). USDA Natural Resources Conservation Service, Technical Notes: Plant Materials No. 47, 14 pp.

Telfer, E.S., 1969. Weight-diameter relationships for 22 woody plant species. Can. J. Bot. 47, 1851-1855.

Ter-Mikaelian, M.T., Korzukhin, M.D., 1997. Biomass equations fort sixty-five North American tree species. For. Ecol. Manage. 97, 1-24.
USDA NRCS (Natural Resources Conservation Service). 2005. COMET VR-CarbOn Management Evaluation Tool for Voluntary Reporting. http://www.cometvr.colostate.edu/ (verified on September 26, 2006).

Wittwer, R.F., Anderson, S., Likens, R., Payne, K., Eisenbraun, E.J., 1999. Biomass and oil content of eastern redcedar (Juniperus virginiana). USDA Forest Service, General Technical Report SRS 30, pp. 546-551.

Zimmerman, P.R., Price, M., Peng, C.H., Capehart, W.J., Updegraff, K., Kozak, P., Vierling, L., Baker, E., Kopp, F., Duke, G., Das, C., 2005. C-Lock (patent pending): a system for estimating and certifying carbon emission reduction credits for the sequestration of soil carbon on agricultural land. Miti. Adapt. Strat. Global Change 10, 307-331. 